- ACORN Australan college of | JOURNAL OF PERIOPERATIVE NURSING

Volume 31 | Issue 4

Article 1

$12-1-2018$

\title{
Current opinion about surgery-related fear and anxiety
}

Follow this and additional works at: https://www.journal.acorn.org.au/jpn

Part of the Health Services Administration Commons, Health Services Research Commons, Perioperative, Operating Room and Surgical Nursing Commons, and the Surgery Commons

(c) (i)

This work is licensed under a Creative Commons Attribution 4.0 License.

\section{Recommended Citation}

Ralph, Nicholas (2018) "Current opinion about surgery-related fear and anxiety," Journal of Perioperative Nursing: Vol. 31 : Iss. 4 , Article 1.

Available at: https://doi.org/10.26550/2209-1092.1046

https://www.journal.acorn.org.au/jpn/vol31/iss4/1

This Article is brought to you for free and open access by Journal of Perioperative Nursing. It has been accepted for inclusion in Journal of Perioperative Nursing by an authorized editor of Journal of Perioperative Nursing. 


\section{ACORN}

The Australian College of Perioperative Nurses (ACORN) is a registered Australian company and health promotion charity. It exists to serve its members, the perioperative profession, the patient and the community to promote the prevention and control of disease.

ACORN's vision is for Australian patients to receive the safest and highest quality evidence-based perioperative care in the world.

\section{ACORN Board of Directors}

Rebecca East

President

\section{Patricia Flood}

Director

Journal Committee Chair

Research Committee Chair

\section{Karen Hay}

Director

Conference Committee Chair

Professional advocacy and advisory

liaison

Diana Hutt

Director

Standards Committee Chair

Grace Loh

Director

Hospital and University Collaboration and Accreditation Committee Chair Grants, Awards and Scholarships

Committee Chair

International liaison

Paula Foran

Member Director

Membership and Local Associations Liaison Committee Chair

Sophie Ehrlich

Director

Education Programs Committee Chair

Education Committee Co-chair

Donna Stevens

Director

Education Committee Co-chair

\section{Garry Stratton}

Director

Finance, Audit and Risk Committee Chair

\section{Editorial}

\section{Current opinion about surgery-related fear and anxiety}

Undergoing a surgical procedure is a major life event for many and can lead to stressors such as heightened fear and associated anxiety. The fear of undergoing surgery or an invasive medical procedure is correctly termed 'tomophobia' and lifetime prevalence is estimated at 12.8 per cent ${ }^{1}$. In Australia, over 2.3 million people report anxiety disorders, with females at greater risk of anxiety (17.9 per cent) than males (10.8 per cent) ${ }^{2}$. With 2.5 million surgical procedures occurring in Australia each year ${ }^{3}$, an estimated 320000 Australians experience tomophobia as a surgical patient (assuming prevalence of 12.8 per cent). However, some populations are more likely to experience surgery-related fear and anxiety: especially females ${ }^{4-6}$, older adults with fewer social supports', those with lower levels of education ${ }^{7-8}$, those undergoing prolonged or major surgery ${ }^{5}$ and those with fewer overall levels of social support ${ }^{9}$.

For all who experience surgeryrelated fear and anxiety, the impact of psychological stress is far from trivial. Preoperative fear and anxiety can lead to increased post-operative depression and anxiety ${ }^{10}$, prolonged wound healing ${ }^{11-12}$, extended length of hospital stay ${ }^{13}$, additional dosing of anaesthetic drugs ${ }^{14}$ and more use of analgesics after surgery ${ }^{15}$. The mechanisms behind these adverse surgical outcomes are likely to involve psychophysiological stress responses associated with preoperative anxiety, the physical trauma of surgery ${ }^{15}$, and its influence on post-operative adjustment and recovery ${ }^{16}$. However, further
Associate Professor Nicholas Ralph PhD, MClinPrac (Perioperative Nursing), RN Journal Editor

\section{Philip Norris}

PhD candidate

high-quality studies are needed to expand on the associated risks of tomophobia in surgery patients. With the evidence indicating the condition is both widespread and leads to surgical complications, how can we address surgery-related fear and anxiety?

Firstly, there is a need to preoperatively screen patients appropriately. In a 2014 crosssectional study, preoperative anxiety screening is recommended for all patients to both identify the extent of the problem and report surgical complications associated with the condition ${ }^{17}$. Several validated surveys are specifically available for surgeryrelated fear and anxiety including the Amsterdam preoperative anxiety and information scale (APAIS) ${ }^{18}$, bypass grafting fear scale (BGFS) ${ }^{19}$ and the surgery stress scale (SSS) for knee surgery ${ }^{20}$. Several generic scales are also available including the statetrait anxiety inventory (STAI) ${ }^{21}$ and the hospital anxiety and depression scale which has been validated in the preoperative context 22,23 . These tools are brief and conducive to most patients being able to complete them independently. However, it is not clear whether all patients should be screened or a subset of those most at risk of preoperative anxiety (i.e. females, older adults, patients undergoing prolonged or major surgery, and those with lower levels of education and social support).

Secondly, there is a need to better understand what interventions are effective for reducing preoperative fear and anxiety. The longstanding association between surgery and psychological stress including fear 
and anxiety is well known ${ }^{24}$ and leads to the argument that the stressors of surgery may be modifiable by psychological or supportive care interventions. However, few effective interventions are available to treat surgery-related fear and anxiety. In a 2015 systematic review of preoperative interventions to reduce anxiety and improve surgical recovery, the effects of educational interventions were inconclusive ${ }^{25}$.

A 2016 study showed that individualised empathic interviewing yielded reductions in overall patient anxiety and improvements in recovery time, wound healing and patient satisfaction ${ }^{26}$ while a similar psychosocial intervention led to reduced anxiety in cardiac surgery patients ${ }^{27}$. For children undergoing surgical procedures, audio-visual interventions appear to be effective for reducing fear and anxiety associated with surgery ${ }^{28}$. Throughout the literature, the importance of integrating sources of social support for patients such as family and friends into the care process is emphasised ${ }^{6,9}$ indicating a place for family-centred care in the perioperative environment.

\section{Implications}

Although studies correlating surgeryrelated anxiety and fear with a range of adverse outcomes is weak, both evidence and logic indicate preoperative anxiety is a widespread condition which needs addressing. Current practice in treating anxiety appears to range from psychoeducation $^{28}$ to sedation ${ }^{14}$. For the latter, sedating people without first appealing to their humanity and honouring the privilege of caring for people at their most vulnerable reflects perioperative care at its least caring.

Interventions for surgery-related anxiety represent an opportunity to improve care by perioperative nurses taking leadership in treating it as they would any other condition. Although proving both the clinical and economic benefits of such interventions is necessary, there is a need to move beyond long-standing, self-limiting professional concepts in which technical skills trump holism. This means perioperative nurses must prioritise the provision of nursing care ahead of passing instruments. There is ample evidence to suggest operative outcomes can be improved through optimising healthy behaviours that enhance nutrition, exercise, sleep and psychological well-being; however, the role of perioperative nurses in these contexts is under-researched and therefore under-developed. With so many perioperative initiatives working towards optimising surgical outcomes $^{29-32}$, it is time that nurses become enterprising and develop interventions targeting the plethora of unmet needs among people undergoing surgery.

\section{References}

1. Schmid M, Wolf RC, Freudenmann RW, Schönfeldt-Lecuona C. Tomophobia, the phobic fear caused by an invasive medical procedure - an emerging anxiety disorder: A case report. J Med Case Rep 2009;18(3:)131.

2. Department of Health. Prevalence of mental disorders in the Australian population [Internet]. Canberra: Department of Health; 2009 [cited 2018 October]. Available from: www.health.gov.au/internet/publications/ publishing.nsf/Content/mental-pubs-mmhaust2-toc mental-pubs-m-mhaust2hig mental-pubs-m-mhaust2-hig-pre.

3. Australian Institute of Health and Welfare (AlHW). Australia's Health 2012: In Brief: AlHW; 2012.

4. Perks A, Chakravarti S, Manninen P. Preoperative anxiety in neurosurgical patients. J neurosurg anesthesiol. 2009;21(2):127-30.

5. Jawaid M, Mushtaq A, Mukhtar S, Khan Z Preoperative anxiety before elective surgery. Neurosciences (Riyadh, Saudi Arabia). 2007;12(2):145-148.

6. Karanci AN, Dirik G. Predictors of pre- and post-operative anxiety in emergency surgery patients. J Psychosom Res 2003;55(4):363-369.
7. Chan CW, Hon HC, Chien WT, Lopez V. Social support and coping in Chinese patients undergoing cancer surgery. Cancer Nurs 2004;27(3):230-236.

8. Celik F, Edipoglu IS. Evaluation of preoperative anxiety and fear of anesthesia using APAIS score. Eur J Med Res 2018;23:41.

9. Lincoln KD, Chatters LM, Taylor RJ. Social support, traumatic events, and depressive symptoms among African Americans. J Marriage Family. 2005;67(3):754-766.

10. Zieger M, Schwarz R, Konig HH, Harter M, Riedel-Heller SG. Depression and anxiety in patients undergoing herniated disc surgery: Relevant but underresearched a systematic review. Cent Eur Neurosurg. 2010;71(1):26-34.

11. Christian LM, Graham JE, Padgett DA, Glaser R, Kiecolt-Glaser JK. Stress and wound healing. Neuroimmunomodulation. 2006;13(5-6):337-346.

12. Vileikyte L. Stress and wound healing. Clin Dermatol. 2007;25(1):49-55.

13. Stirling L, Raab G, Alder EM, Robertson F. Randomized trial of essential oils to reduce perioperative patient anxiety: Feasibility study. J Adv Nurs 2007;60(5):494-501.

14. Maranets I, Kain ZN. Preoperative anxiety and intraoperative anesthetic requirements. Anesth Analg 1999;89(6):1346-1351.

15. Munafo MR, Stevenson J. Anxiety and surgical recovery. Reinterpreting the literature. J Psychosom Res 2001;51(4):589-596.

16. Wallace LM. Preoperative state anxiety as a mediator of psychological adjustment to and recovery from surgery. Br J Med Psychol 1986;59(3):253-261.

17. Theunissen M, Peters ML, Schouten EGW, Fiddelers AAA, Willemsen MGA, Pinto PR et al. Validation of the surgical fear questionnaire in adult patients waiting for elective surgery. PLOS ONE 2014;9(6):e100225.

18. Moerman N, van Dam FS, Muller MJ, Oosting $\mathrm{H}$. The Amsterdam Preoperative Anxiety and Information Scale (APAIS). Anesth Analg 1996;82(3):445-451.

19. Koivula M, Tarkka M-T, Tarkka M, Laippala $P$, Paunonen-Ilmonen M. Fear and in-hospital social support for coronary artery bypass grafting patients on the day before surgery. Int J Nurs Stud 2002;39(4):415-427.

20. Rosenberger PH, Kerns R, Jokl P, Ickovics JR. Mood and attitude predict pain outcomes following arthroscopic knee surgery. Ann Behav Med 2009;37(1):70-76.

21. Spielberger CD. Chapter 14. Conceptual and methodological issues in anxiety research. In: Spielberger CD (ed). Anxiety. New York: Academic Press, 1972, 481-493. 
22. Zigmond AS, Snaith RP. The hospital anxiety and depression scale. Acta Psychiatr Scand 1983;67(6):361-370.

23. Hicks JA, Jenkins JG. The measurement of preoperative anxiety. J R Soc Med 1988;81(9):517-519.

24. Salmon P. Psychological factors in surgical stress: Implications for management. Clin Psychol Rev 1992;12(7):681-704.

25. Guo P. Preoperative education interventions to reduce anxiety and improve recovery among cardiac surgery patients: A review of randomised controlled trials. J Clin Nurs 2015;24(1-2):34-46.
26. Pereira L, Figueiredo-Braga M, Carvalho IP. Preoperative anxiety in ambulatory surgery: The impact of an empathic patientcentered approach on psychological and clinical outcomes. Patient Educ Couns 2016;99(5):733-738.

27. Heilmann C, Stotz U, Burbaum C, Feuchtinger J, Leonhart R, Siepe $M$ et al. Short-term intervention to reduce anxiety before coronary artery bypass surgery - a randomised controlled trial. J Clin Nurs 2016;25(3-4):351-61.

28. Chow CHT, Van Lieshout RJ, Schmidt LA, Dobson KG, Buckley N. Systematic review: Audiovisual interventions for reducing preoperative anxiety in children undergoing elective surgery. J Pediatr Psychol 2016;41(2):182-203.
29. Ralph N. Editorial: Engaging with research and evidence is a nursing priority so why are 'everyday' nurses not reading the literature? Journal of Perioperative Nursing 2017;30(3):3-5

30. Duff J, Walker K, Edward KL, Ralph N, Giandinoto JA, Alexander K et al. Effect of a thermal care bundle on the prevention, detection and treatment of perioperative inadvertent hypothermia. J Clin Nurs 2018;27(5-6):1239-49.

31. Ralph N, Duff J. Editorial: Enhanced Recovery After Surgery (ERAS) protocols - an opportunity for improved care and enhanced scope of practice? Journal of Perioperative Nursing 2017;30(2):3-4.

32. Ralph N, Eager A. Editorial: Post-operative oxygen supplementation: Can it prevent surgical site infections? Journal of Perioperative Nursing 2017;30(4):3-4. 